\title{
Selective Toxicity of a Highly Potent Camptothecin Analogue: A Pilot Study with Glioblastoma Multiforme Cells
}

\author{
GARRET YOUNT, LILIANA SOROCEANU, HUI-JUAN WANG, ERIC SINGER, \\ ROMI YOUNT, TRAN LUU and LI-XI YANG \\ California Pacific Medical Center Research Institute, San Francisco, CA, U.S.A.
}

\begin{abstract}
Background/Aim: We developed a novel camptothecin analogue, CPT417, that yields reduced toxicity compared to other analogues used in chemotherapeutic regimens. In this pilot study, we assessed the activity of CPT417 against glioblastoma multiforme (GBM) cells and glioma stem cells. Materials and Methods: The human U251 GBM cell line and normal human astrocytes were cultured in parallel for clonogenic survival analysis following exposure to increasing concentrations of CPT417. Cell viability of a glioma stem cell line was assessed 5 days after exposure to a range of CPT417 concentrations. Results: CPT417 completely inhibited clonogenic survival of GBM cells at $10 \mathrm{nM}$, whereas this concentration only inhibited astrocytes by approximately 50\%. Cell viability analysis of glioma stem cell cultures yielded a half-maximal response at 15 nM. Conclusion: CPT417 acts selectively against GBM cells at concentrations that are at least an order of magnitude below reported values for related alkylating agents in clinical use.
\end{abstract}

Alkylating agents, such as temozolomide (TMZ) and camptothecin (CPT) analogues, are popular adjuvant chemotherapies against glioblastoma multiforme (GBM) due to their effectiveness as DNA damaging agents $(1,2)$. An important mechanism by which these agents cause DNA damage is through their inhibition of topoisomerase 1 (Topo1). Topo1 forms a bond with DNA during replication, catalyzing a forward reaction in which DNA is cleaved to allow unwinding, and a reverse reaction in which DNA is religated (3). CPT analogues interfere with the re-ligation step

Correspondence to: Li-Xi Yang, California Pacific Medical Center Research Institute, 475 Brannan Street, Suite 220, San Francisco, CA, 94107, U.S.A. Tel: +1 4156006203, Fax: +1 4156006215, e-mail: Yangl@cpmcri.org

Key Words: Glioma, CPT417, alkylating agents, selective efficacy, temozolomide. of this process by reversibly binding to and stabilizing the enzyme/DNA complex. The subsequent collision between the enzyme/DNA complex and the replication fork during $S$ phase is thought to result in DNA double strand breaks that eventually lead to cell death (4). CPT analogues have also been shown to have anti-tumor activity by blocking RNA synthesis (5) and inhibiting checkpoint kinase 1 (Chk1) (6). Chk1 is a kinase that plays a key role in the DNA damageinduced checkpoint network. When the $\mathrm{G}_{2}$ or $\mathrm{S}$ checkpoint is abrogated by the inhibition of Chk1, cells undergo mitotic catastrophe and eventual apoptosis $(7,8)$. Thus, Chk1 inhibitors have been proposed as a mechanism-based means of increasing the efficacy of DNA-damaging agents in both p53 wild-type and p53 mutant glioma cells $(9,10)$. For example, synergistic anti-tumor activities have been reported for the combination of Chk1 inhibitors and Topo1 poisons, including CPT (11). Further anti-tumor activity is likely contributed by their ability to hypoxia-inducible factor $1 \alpha$ (HIF-1 $\alpha$ ), which regulates the transcriptional response to oxygen deprivation and enables tumors to adapt to hypoxia. Thus, cell-cycle checkpoint abrogation through Chk1 inhibition has been proposed as one way that CPT analogues act against cancer cells in addition to, and potentially synergistic with, inducing DNA-damage.

Despite the success of alkylating agents in clinical use, the increases in survival achieved thus far must be weighed against the significant side-effects resulting from their toxicity. A major contributing factor to the toxic side-effects associated with current CPT analogues is the intrinsic instability of the lactone ring in the CPT molecular structure (key active component) (12-18). The instability results in an inactive ring-opened carboxylate in plasma that causes both decreased potency and increased toxicity as the specific antitopoisomerase activity is lost and the carboxylate is generally harmful. To remedy this, we develop a series of novel CPT analogues with the aim of increasing the steric hindrance at the $\mathrm{C} 20$ (S) position of the lactone to enhance its intrinsic stability under physiological conditions. One new CPT analogue with a 2-carbon ester chain attached with 4- 
a

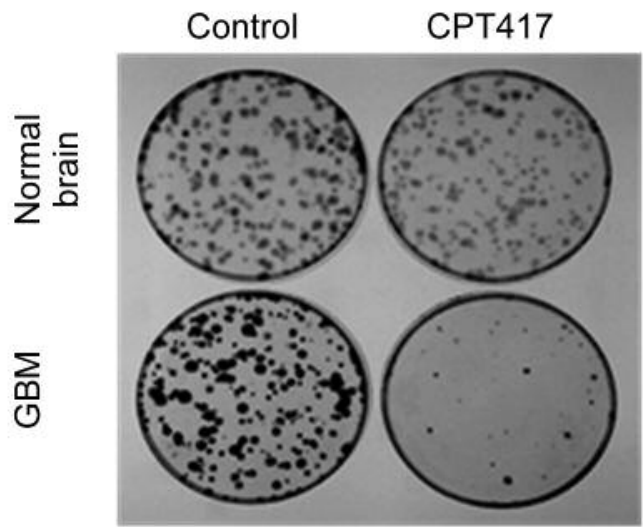

b

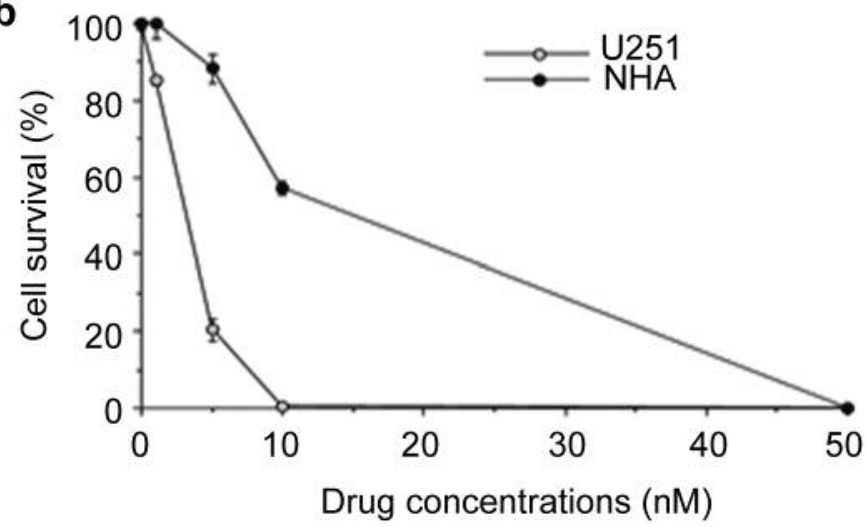

Figure 1. CPT417 selectively inhibits GBM cell clonogenicity. Clonogenic survival following exposure to CPT417 was assessed in cultures of U251 GBM cells or normal human astrocytes (NHA). a) Representative plates showing colony formation at $5 \mathrm{nM}, \mathrm{b}$ ) Dose-response curves for clonogenic survival of U251 GBM cells compared to NHA. Triplicate wells were exposed to increasing doses of CPT417 for 72 h. Colonies of $>50$ cells were counted after 14 days of incubation and plotted with standard deviation.

fluorophenoxy group at the $\mathrm{C} 20(\mathrm{~S})$ position, termed CPT417, showed particular promise (19). We previously reported that CPT417 exhibits dramatically reduced toxicity in vivo while retaining potent anti-tumor activity against mammary adenocarcinoma tumors in a subcutaneous flank model and against human GBM cells in culture. This work extends the investigation of CPT417 by assessing the potential for this novel CPT analogue to act selectively against GBM cells compared to normal glial cells.

\section{Materials and Methods}

GBM cell culture. The human U251 GBM cell line was purchased from ATCC (Manassas, VA, USA) and maintained as an exponentially growing monolayer culture at $37^{\circ} \mathrm{C}$ and $5 \% \mathrm{CO}_{2}$ in RPMI media supplemented with $50 \mathrm{ng} / \mathrm{ml}$ gentamicin, $50 \mathrm{ng} / \mathrm{ml}$ amphotericin, penicillin, streptomycin and $10 \%$ fetal bovine serum. All experimental cells were passaged at confluence using trypsinization and expanded to a large population size, aliquoted and frozen viably for long-term storage. A fresh aliquot was thawed at the start of each experimental trial to ensure uniformity in the genetic profile of the target cells throughout the experiments. A normal human astrocyte (NHA) culture was purchased (Clonetics, Sacramento, CA, USA) grown in Clonetics ${ }^{\mathrm{TM}}$ AGM $^{\mathrm{TM}}$ Primary Astrocyte Growth Media. For parallel experiments with normal astrocytes, U251 cells were pre-adapted in astrocyte media for 4 days.

A primary glioma stem cell culture generated using tissue obtained during surgical resection of a patient diagnosed with GBM (3832) was obtained from Dr. Jeremy Rich (Cleveland Clinic, Cleveland, OH, USA) in accordance with Institutional Review Board approved protocols. Resected GBM tissue was subjected to enzymatic digestion, mechanical dissociation and single-cell suspensions were cultured using neural basal medium $+\mathrm{N}_{2}$ supplement, $20 \mathrm{ng} / \mathrm{ml} \mathrm{EGF,} 20 \mathrm{ng} / \mathrm{ml}$ basic fibroblast growth factor and heparin $5 \mathrm{ng} / \mathrm{ml}$. GBM 3832 was authenticated using the
Promega STR assay (Promega, Sunnyvale, CA, USA) and used within five passages.

Clonogenic survival. Six-well plates were prepared with a feeder layer of lethally irradiated U251 GBM cells. On the following day, exponentially growing cultures of the experimental cells were treated with either CPT417 or an equal volume of DMSO (vehicle control). Triplicate wells were then incubated for 21 days and colonies of $>50$ cells were counted. Survival was assessed at multiple densities.

Cell viability assay. Viability assays for dose response were performed by seeding cells at 10,000 cells/well in triplicates into 96-well plates containing the appropriate growth media. Cells were allowed to recover overnight and, then, growth media was supplemented with either CPT417 to the desired final concentrations or an equal volume of DMSO. Viability was assessed after 5 days using Cell Titer-GLO Luminescent Cell Viability Assay (Promega). Data shown are representative of an $n \geq 6$ for all data points and all data analysis was performed using GraphPad Prism (GraphPad Software, Inc., La Jolla, CA, USA).

\section{Results}

The potential for selective anti-tumor activity was assessed through parallel assessments of GBM cells and normal astrocyte cells. We compared clonogenic survival of U251 GBM cells and normal human astrocytes cultured side-by-side and found that CPT417 was much more active against the GBM cells. A low nanomolar concentration of CPT417 (5 nM) was sufficient to inhibit U251 GBM colony formation by approximately $78 \%$ while only inhibiting the normal cells by approximately $13 \%$ (Figure 1). The colony formation of U251 cells was inhibited by CPT417 completely at a concentration of $10 \mathrm{nM}$, whereas the concentration required to completely inhibit normal cells was $50 \mathrm{nM}$. 


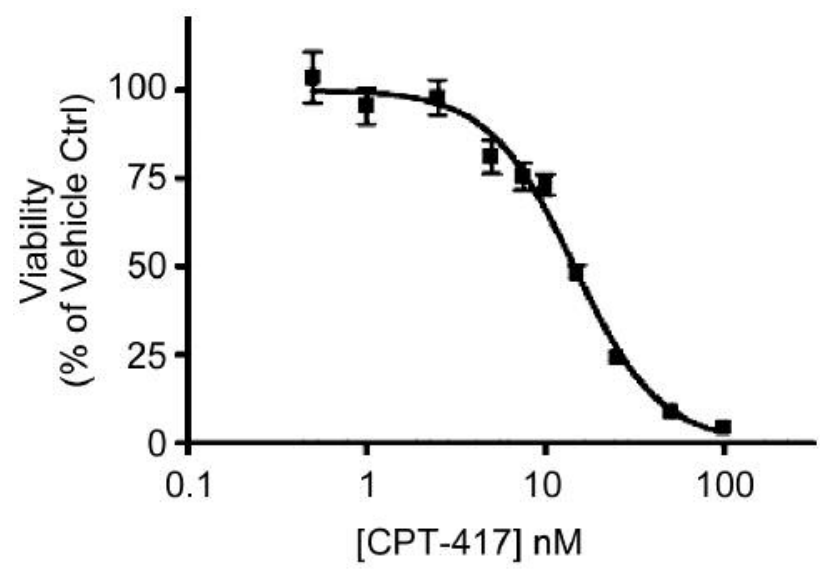

Figure 2. CPT417 is highly potent against primary GBM cells. Primary glioma stem cell cultures (GBM 3832) were exposed to increasing concentrations of CPT417 and cultured for 5 days, after which the viability of the cells was assessed. All viability data are presented as $\%$ value of control cultures treated with vehicle (with a final concentration of $0.1 \%$ DMSO in all wells).

These provocative results prompted us to assess the potency of CPT417 against glioma stem cells because this subpopulation of GBM tumor cells has been shown to resist or adapt to standard therapies, leading to therapeutic resistance. The primary glioma stem cell line 3832 was treated with a range of CPT417 concentrations and evaluated in viability assays (Figure 2). The concentration of CPT417 that gives half-maximal response $\left(\mathrm{EC}_{50}\right)$ is in the low nanomolar range $\left(14.48 \mathrm{nM} ; \mathrm{R}_{2}=0.95\right)$, while the $\mathrm{EC}_{50}$ for temozolomide against this glioma stem cell line is in the micromolar range $(\sim 250 \mu \mathrm{M}$; data not shown).

\section{Discussion}

GBM is highly resistant to conventional chemotherapy, in part due to the very poor penetration of drugs across the blood-brain barrier (BBB). In addition to the tight junctions of the BBB, the ATP-dependent efflux transporters that limit drug cellular accumulation $(20,21)$ play a critical role in its drug-resistance. The most prominent of these BBB transporters is P-glycoprotein. The drug-transporting Pglycoprotein is expressed at the luminal membranes of endothelial cells of the $\operatorname{BBB}(22,23)$. Its ability to handle a large number of chemotherapeutic drugs is a major impediment to central nervous system pharmacotherapy (21) and there is evidence that P-glycoprotein can limit brain distribution of its substrates even under conditions in which the tight junctions of the BBB are disrupted $(24,25)$. Within this context, the results of our previous study demonstrating that CPT417 can effectively overcome the multidrug- resistance caused by P-glycoprotein (19) and its high lipophilicity suggest that CPT417 will efficiently penetrate the $\mathrm{BBB}$. The results reported here indicate that, once across the BBB, CPT417 may display selective toxicity against GBM cells compared to normal surrounding tissue.

The apparent preferential activity of CPT417 against GBM cells compared to normal human astrocytes establishes this novel alkylating agent as a promising candidate for use in the treatment of this common primary brain tumor that poses significant therapeutic challenges. The relevance of these preliminary data is strengthened by the fact that the U251 GBM cell line expresses mutant p53, which results in loss of wild-type p53 tumor suppressor activity, as well as increased oncogenic properties contributing to therapeutic resistance (26). Additionally, we were also interested to assess CPT417's activity against primary glioma stem cell cultures because it is known that cancer stem cells can contribute to GBM radioresistance by an increase of DNA repair capacity through preferential activation of the DNA damage response checkpoints (27, 28). We found that CPT417 is highly potent against glioma stem cells with an $\mathrm{EC}_{50}$ in the low nanomolar range. Importantly, this concentration is at least 10-times lower than that achieved against these same cells by temozolomide. Thus, these results provide compelling rationale for further characterization of CPT417 as a nontoxic therapeutic agent and inspire genuine hope that this study could ultimately lead to radically improved treatment options for GBM patients.

\section{Acknowledgements}

We are grateful to Dr. Jeremy Rich (Cleveland Clinic, Cleveland, $\mathrm{OH}, \mathrm{USA}$ ) for the 3832 primary glioma stem cell culture.

\section{References}

1 Kim YH, Lee JK, Kim B, DeWitt JP, Lee, JE, Han JH, Kim SK, Oh CW and Kim CY: Combination therapy of cilengitide with belotecan against experimental glioblastoma. Int J Cancer 133: 749-757, 2013

2 Su J, Cai M, Li W, Hou B, He H, Ling C, Huang T, Liu H and Gua Y: Molecularly targeted drugs plus radiotherapy and temozolomide treatment for newly diagnosed glioblastoma: A meta-analysis and systematic review. Oncology Research 24: 117-128, 2016.

3 Tse, YC, Kirkegaard K and Wang JC: Covalent bonds between protein and DNA. Formation of phosphotyrosine linkage between certain DNA topoisomerases and DNA. J Biol Chem 255(12): 5560-5565, 1980. Available at: http://www.jbc.org/ content/255/12/5560.long

4 Hsiang YH, Hertzberg R, Hecht S and Liu LF: Camptothecin induces protein-linked DNA breaks via mammalian DNA topoisomerase I. J Biol Chem 260(27): 14873-14878, 1985. Available at: http://www.jbc.org/content/260/27/14873.long 
5 Bendixen C, Thomsen B, Alsner $\mathrm{J}$ and Westergaard O: Camptothecin-stabilized topoisomerase I-DNA adducts cause premature termination of transcription. Biochemistry 29(23): 5613-5619, 1990 .

6 Legarza K and Yang LX: New molecular mechanisms of action of camptothecin-type drugs. Anticancer Res 26: 3301-3306, 2006. Available at: http://ar.iiarjournals.org/content/26/5A/ 3301.long

7 Tao ZF and Lin NH: Chk1 inhibitors for novel cancer treatment. Anticancer Agents Med Chem 6(4): 377-388, 2006.

8 Xiao Z, Xue J, Sowin TJ, Zhang H: Differential roles of checkpoint kinase 1 , checkpoint kinase 2, and mitogen-activated protein kinase-activated protein kinase 2 in mediating DNA damage-induced cell cycle arrest: Implications for cancer therapy. Mol Cancer Ther 5(8): 1935-1943, 2006.

Available at: http://mct.aacrjournals.org/content/5/8/1935.long

9 Hirose Y, Berger MS and Pieper RO: Abrogation of the Chk1mediated $\mathrm{G}(2)$ checkpoint pathway potentiates temozolomideinduced toxicity in a p53-independent manner in human glioblastoma cells. Cancer Res 61(15): 5843-5849, 2001. Available at: http://cancerres.aacrjournals.org/content/ 61/15/5843.long

10 Gao Q, Huang X, Tang D, Cao Y, Chen G, Lu Y, Zhuang L, Wang S, Xu G, Zhou J and Ma D: Influence of chk1 and plk1 silencing on radiation- or cisplatin-induced cytotoxicity in human malignant cells. Apoptosis 11(10): 1789-1800, 2006.

11 Tao ZF, Wang L, Stewart KD, Chen Z, Gu W, Bui MH, Merta P, Zhang H, Kovar P, Johnson E, Park C, Judge R, Rosenberg S, Sowin $\mathrm{T}$ and Lin NH: Structure-based design, synthesis, and biological evaluation of potent and selective macrocyclic checkpoint kinase 1 inhibitors. J Med Chem 50(7): 1514-1527, 2007.

12 Sawada S, Okajima S, Aiyama R, Nokata K, Furuta T, Yokokura T, Sugino E, Yamaguchi K and Miyasaka T: Synthesis and antitumor activity of 20(S)-camptothecin derivatives: Carbamate-linked, water-soluble derivatives of 7-ethyl-10-hydroxycamptothecin. Chem Pharm Bull (Tokyo) 39(6): 1446-1450, 1991.

13 Subrahmanyam D, Sarma VM, Venkateswarlu A, Sastry TV, Srinivas AS, Krishna CV, Deevi DS, Kumar SA, Babu MJ and Damodaran NK: Novel C-ring analogues of 20(S)-camptothecin. Part 3: Synthesis and their in vitro cytotoxicity of A-, B- and Cring analogues. Bioorg Med Chem Lett 10(4): 369-371, 2000.

14 Jew SS, Kim MG, Kim HJ, Rho EY, Park HG, Kim JK, Han HJ and Lee H: Synthesis and in vitro cytotoxicity of C(20)(RS)camptothecin analogues modified at both $\mathrm{B}$ (or A) and $\mathrm{E}$ ring. Bioorg Med Chem Lett 8(14): 1797-1800, 1998.

15 Bailly C: Homocamptothecins: Potent topoisomerase I inhibitors and promising anticancer drugs. Crit Rev Oncol Hematol 45(1): 91-108, 2003

16 Lavergne O, Lesueur-Ginot L, Pla Rodas F, Kasprzyk PG, Pommier J, Demarquay D, Prévost G, Ulibarri G, Rolland A, Schiano-Liberatore AM, Harnett J, Pons D, Camara J and Bigg DC: Homocamptothecins: Synthesis and antitumor activity of novel E-ring-modified camptothecin analogues. J Med Chem 41(27): 5410-5419, 1998.

17 Lavergne O, Demarquay D, Kasprzyk PG and Bigg DC. Homocamptothecins: E-ring modified CPT analogues. Ann NY Acad Sci 922: 100-111, 2000.
18 Lavergne O, Lesueur-Ginot L, PLa rodas $\mathrm{F}$ and Bigg DC: BN80245: an E-ring modified camptothecin with potent antiproliferative and topoisomerase I inhibitory activities. Bioorg Med Chem Lett 7: 2235-2238, 1997.

19 Yang LX, Pan X and Wang HJ: Novel camptothecin derivatives. Part 1: Oxyalkanoic acid esters of camptothecin and their in vitro and in vivo antitumor activity. Bioorg Med Chem Lett 12(9): 1241-1244, 2002.

20 Hawkins, BT and Davis TP: The blood-brain barrier/ neurovascular unit in health and disease. Pharmacol Rev 57(2): 173-185, 2005. Available at: http://pharmrev.aspetjournals.org/ content $/ 57 / 2 / 173$. long

21 Miller DS, Bauer B and Hartz AM: Modulation of Pglycoprotein at the blood-brain barrier: opportunities to improve central nervous system pharmacotherapy. Pharmacol Rev 60(2): 196-209, 2008. Available at: http://pharmrev.aspetjournals.org/ content/60/2/196.long

22 Cordon-Cardo C, O'Brien JP, Casals D, Rittman-Grauer L, Biedler JL, Melamed MR and Bertino JR: Multidrug-resistance gene (P-glycoprotein) is expressed by endothelial cells at bloodbrain barrier sites. Proc Natl Acad Sci USA 86(2): 695-869, 1989. Available at: http://www.pnas.org/content/86/2/695.long

23 Thiebaut F, Tsuruo T, Hamada H, Gottesman MM, Pastan I and Willingham MC: Immunohistochemical localization in normal tissues of different epitopes in the multidrug transport protein P170: evidence for localization in brain capillaries and crossreactivity of one antibody with a muscle protein. J Histochem Cytochem 37(2): 159-64, 1989. Available at: http://jhc.sagepub.com/content/37/2/159.long

24 Spudich A, Kilic E, Xing H, Kilic U, Rentsch KM, WunderliAllenspach H, Bassetti CL and Hermann DM: Inhibition of multidrug resistance transporter-1 facilitates neuroprotective therapies after focal cerebral ischemia. Nat Neurosci 9(4): 487488, 2006.

25 Seelbach MJ, Brooks TA, Egleton RD and Davis TP: Peripheral inflammatory hyperalgesia modulates morphine delivery to the brain: A role for P-glycoprotein. J Neurochem 102(5): 1677-90, 2007. Available at: http://onlinelibrary.wiley.com/doi/ 10.1111/j.1471-4159.2007.04644.x/full

26 Strano S, Dell'Orso S, Di Agostino S, Fontemaggi G, Sacchi A and Blandino G: Mutant p53: an oncogenic transcription factor. Oncogene 26: 2212-2219, 2007. Available at: http:// www.nature.com/onc/journal/v26/n15/full/1210296a.html

27 Bao S, Wu Q, McLendon RE, Hao Y, Shi Q, Hjelmeland AB, Dewhirst MW, Bigner DD and Rich JN: Glioma stem cells promote radioresistance by preferential activation of the DNA damage response. Nature 444(7120): 756-760, 2006.

28 Beier D, Schulz JB and Beier CP: Chemoresistance of glioblastoma cancer stem cells - much more complex than expected. Mol Cancer 10: 128, 2011. Available at: http:// www.ncbi.nlm.nih.gov/pmc/articles/PMC3207925/

Received August 11, 2016

Revised August 29, 2016

Accepted August 30, 2016 